\title{
Research Article \\ Study on the Surge-Swab Pressure considering the Effect of the Cutting Plug in Shale Drilling
}

\author{
Tianyi Tan $\left(\mathbb{D}\right.$, Hui Zhang $\mathbb{D}^{D}$, Xusheng Ma, and Yufei Chen \\ College of Petroleum Engineering, China University of Petroleum-Beijing, 102249, China \\ Correspondence should be addressed to Hui Zhang; zhanghuicup@163.com
}

Received 7 September 2021; Accepted 5 November 2021; Published 26 November 2021

Academic Editor: Afshin Davarpanah

Copyright (c) 2021 Tianyi Tan et al. This is an open access article distributed under the Creative Commons Attribution License, which permits unrestricted use, distribution, and reproduction in any medium, provided the original work is properly cited.

\begin{abstract}
Wellbore instability is a frequent problem of shale drilling. Accurate calculation of surge-swab pressures in tripping processes is essential for wellbore pressure management to maintain wellbore stability. However, cutting plugs formed in shale horizontal wells have not been considered in previous surge-swab pressure models. In this paper, a surge-swab pressure model considering the effect of cutting plugs is established for both open pipe string and closed pipe string conditions; In this model, the osmotic pressure of a cutting plug is analyzed. The reduction of cutting plug porosity due to shale hydration expansion and dispersion is considered, ultimately resulting in an impermeable cutting plug. A case study is conducted to analyze swab pressures in a tripping out process. The results show that, in a closed pipe condition, the cutting plug significantly increases the swab pressures below it, which increase with the decrease of cutting plug porosity and the increase of cutting plug length. Under the give condition, the swab pressure at the bottom of the well increases from $3.60 \mathrm{MPa}$ to $8.82 \mathrm{MPa}$ due to the cutting plug, increasing by $244.9 \%$. In an open pipe string condition, the cutting plug affects the flow rate in the pipes and the annulus, resulting in a higher swab pressure above the cutting plug compared to a no-cutting plug annulus. The difference increases with the decrease of the porosity and the increase of the length and the measured depth of the cutting plug. Consequently, the extra surge-swab pressures caused by cutting plugs could result in wellbore pressures out of safety mud density window, whereas are ignored by previous models. The model proposes a more accurate wellbore pressure prediction and guarantees the wellbore stability in shale drilling.
\end{abstract}

\section{Introduction}

As a fossil resource preserved in nanoscale pores in organicrich shale, shale oil is now an essential part of the world energy market [1]. In 2018, the production of shale oil was $23.49 \times 10^{8} \mathrm{bbl}$ in the U.S., accounting for $64.7 \%$ of the total petroleum output [2]. In 2040, the productivity is estimated as $94.6 \times 10^{5} \mathrm{bbl} / \mathrm{d}$. In China, the technically recoverable shale oil is estimated as $55 \times 10^{8} \mathrm{t}$, making up $9.7 \%$ of the technically recoverable shale oil resource in the whole world [3], mainly distributed in Jilin, Daqing, and the northwest of China [4]. Due to the exhaustion of conventional oil and gas resources, shale oil has been considered as one of the most promising energy sources in the future [4]. However, along with the great prospect of shale oil, significant challenges still exist. The horizontal well drilling in a shale formation is the kernel technique to exploit shale oil. Due to the special tra- jectory of horizontal wells and the unique characteristics of shale formation, problems caused by wellbore instability are frequent in drilling engineering. Accidents like borehole collapse, loss of drilling fluid and pipe sticking result in vast nonproductive time, and tremendous economic losses.

Wellbore stability is the core of safe and efficient drilling. To guarantee wellbore stability in shale formations, the wellbore pressure should be kept in an allowable range (safety mud density window) during a drilling process [5]. In general, the upper limit of the allowable range is the formation fracture pressure. With the wellbore pressure higher than the formation fracture pressure, tensile failure occurs in the wellbore rock [6], and drilling fluid flows into the formation through these fractures. This harmful drilling fluid loss defined as lost circulation [7] entails various problems [8] like consumption of enormous drilling fluid, inefficient cutting transportation, and reservoir pollution. Especially for 
shale drilling, the fluid loss aggravates the hydration of shale formation, resulting in further wellbore instability problems. The lower limit of the allowable range is determined by the larger one between the formation collapse pressure and the formation pore pressure. With the wellbore pressure lower than the formation collapse pressure, shear failure forms in the borehole rock and wellbore collapse occurs [6]. Wellbore collapse results in drilling problems like pipe sticking and borehole expansion. With the wellbore pressure lower than the formation pore pressure, formation fluid flows into the wellbore due to the hydraulic imbalance, defined as fluid influx. The fluid influx might induce serious drilling problems like well kick and blowout. Accidents caused by unsuccessful wellbore pressure management have resulted in enormous financial loss, nonproductive time, and even casualties $[8,9]$.

Most of the wellbore instability problems occur in tripping in/out processes, due to surge-swab pressures caused by pipe string movements. By definition, surge-swab pressures are the additional pressures generated by axial movements of the drilling string in the wellbore [10]. The research of surge-swab pressures has been started at an early time. Cannon [11] conducted tests to measure pressure changes with downhole pressure gauges when withdrawing pipes, regarding that the pipe withdrawing entails wellbore pressure reduction and might lead to blow-out accidents. Later, more experiments were conducted, and field data was investigated about surge-swab pressures [12-16], mostly for validation and improvement of theoretical models. Besides experimental work, theoretical studies are dedicated to establishing models of the surge-swab pressure, including steady-state models and dynamic (or transient) models. Clark [17] proposed semiempirical formulas of equivalent velocities for steady-state surge-swab pressure calculation. The pressure caused by fluid acceleration was also considered in his work. Burkhardt [18] established a surge-swab pressure model with theoretical studies, proposing the graph of mud clinging constant for convenient use. Fontenot and Clark [19] established a comprehensive steady surge-swab pressure model considering the drilling fluid property variation with depth. Subsequent work on steady-state surgeswab pressure has been dedicated to improving the model with various optimizations. Wang and Liu [20] established the steady-state surge-swab pressure model for RobertsonStiff fluid, which is also a kind of yield-pseudoplastic fluid. In the work of Wang et al. [21], the effect of pipe eccentricity was considered on Newtonian drilling fluid. Crespo et al. [22] established a steady-state model taking account of fluid and formation compressibility and pipe elasticity for yield power-law (YPL) fluid. Later in 2013, a laboratory experiment was conducted, and a regression model of surge-swab pressures was developed for YPL fluid [23]. Tang et al. [24] established a steady-state model considering the effect of the drilling string velocity on the boundary condition. Ettehadi and Altun [25] established a steady-state model for Hershel-Bulkley (HB) fluid and applied in situ thermal rheological measurements to amend rheological parameters of drilling fluid. Krishna et al. [26] proposed explicit flow velocity equations for steady-state surge-swab pressure models of yield power law fluid to achieve more convenient calculation. The dynamic model (or transient model) is another route to deal with the issue of the surge-swab pressure [27-31]. Different from steady-state models, dynamic models take account of the elasticity of the pipes and the wellbore, the inertia and compressibility of drilling fluid, and the variation of tripping velocity [10]. Due to complexity of calculation, dynamic models are difficult to be applied in field drilling practice.

As noted above, scores of researches have been conducted on the surge-swab pressure in drilling engineering. However, in shale formation drilling, the effect of an influential phenomenon on the surge-swab pressure has not been considered in existing studies: the effect of a cutting plug. Due to the low permeability of the reservoirs, horizontal wells are essential in the development of shale oil. Wellbore uncleanness is a prominent problem of horizontal well drilling. Cutting particles are easy to accumulate in a horizontal wellbore, and cutting plugs might be formed when pump is stopped and tripping processes are conducted. Different from a cutting bed, a cutting plug fills the annulus at a certain length [32]. Fluid flow in tripping in and tripping out processes is affected by this particular accumulation of cutting particles. Excessive wellbore pressures under a cutting plug condition are not able to be predicted by previous models, resulting in the wellbore instability risk of shale drilling. In this article, a surge-swab model considering the effect of a cutting plug is established for both open pipe string and closed pipe string conditions. The porosity variety of the shale cutting plug is also considered. Finally, a case study is conducted to give a deeper insight.

\section{Formation of Cutting Plugs}

The cutting plug is a cutting particle cylinder in the annulus between the drilling string and the wellbore formed in three conditions (Figure 1): (1) the cuttings accumulated at a borehole-enlarged section slide down due to the disturbance of the tripping pipe string, (2) the cuttings in the vertical and small-inclination sections settle down and accumulate in the large-inclination and horizontal sections when circulation is stopped, and (3) the cuttings at the lower side of the wellbore as a cutting bed are pushed and accumulated by the large diameter tools in repetitive reaming or tripping processes like the bulldozer work.

\section{Establishment of Model}

3.1. Assumptions. To develop the model, following assumptions are made: (1) the drilling fluid is incompressible, (2) for the accurate description of drilling fluid rheological properties and the simplicity of expression [33], power-law flow pattern is considered for the drilling fluid, (3) the rheology of the drilling fluid is assumed constant, ignoring the effect of temperature and pressure, (4) the drilling string and the wellbore are rigid, (5) the drilling string is concentric in the wellbore, and (6) the effect of cutting particles out of the cutting plug is overlooked. 


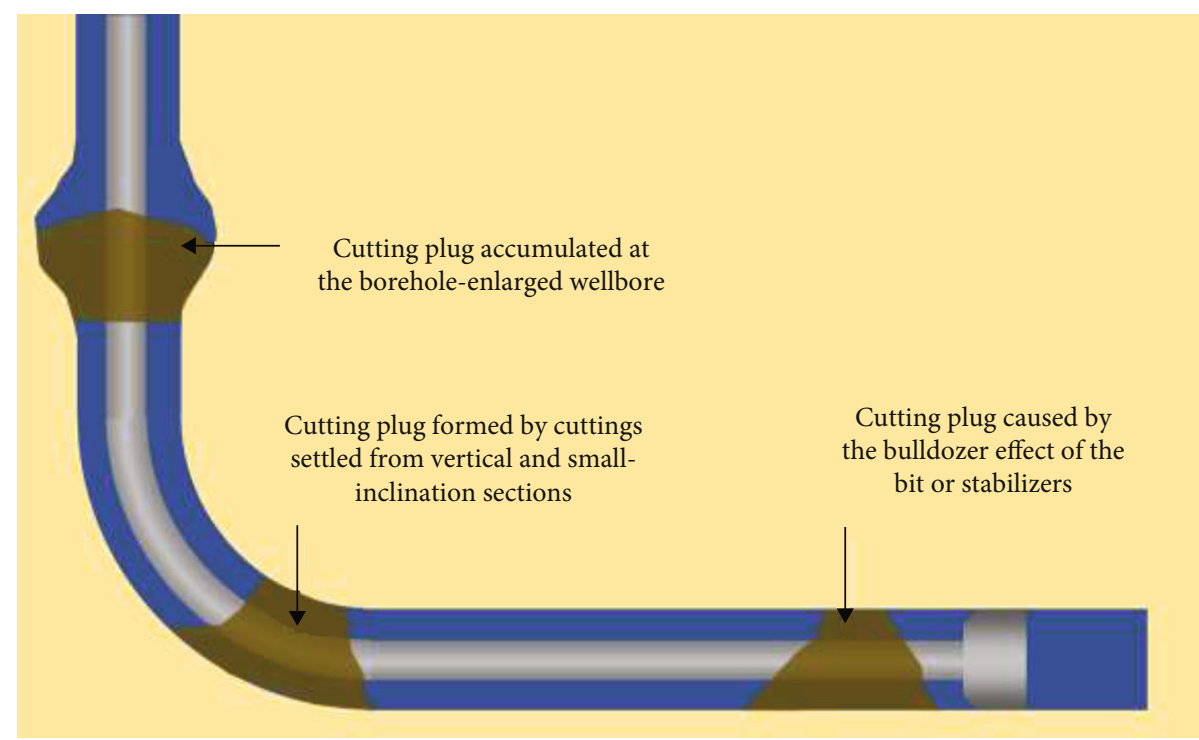

FIgURE 1: The sketch of cutting plugs formed in a shale horizontal well.

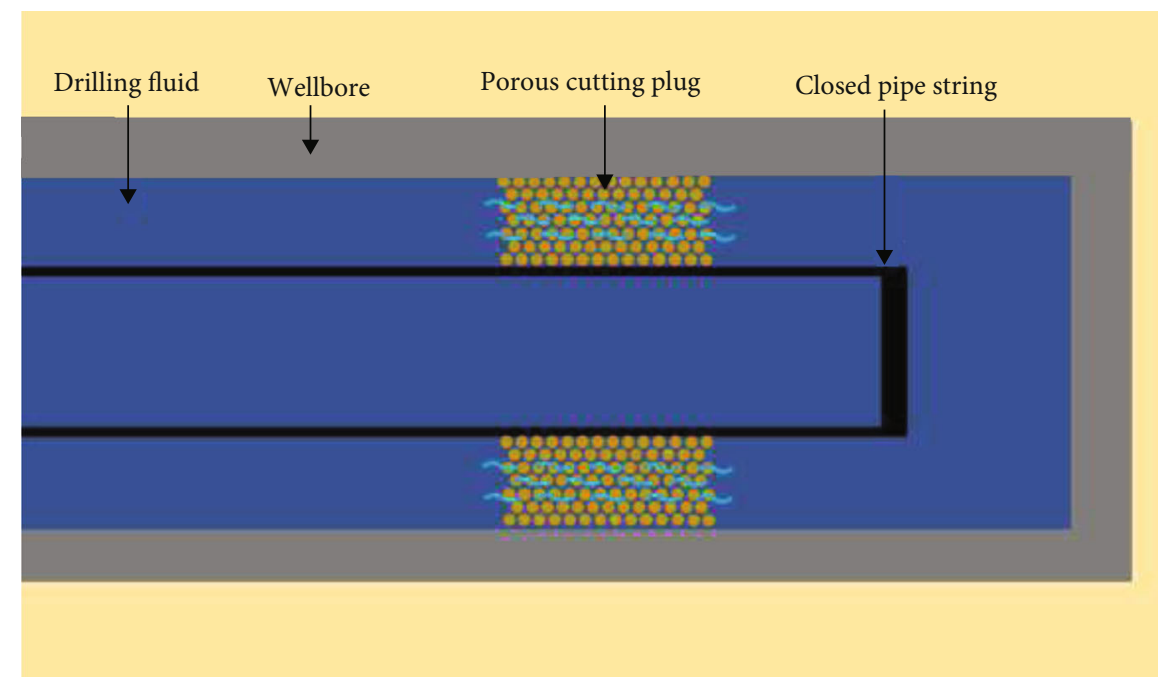

Figure 2: A closed pipe string with a porous cutting plug.

3.2. Closed Pipe String. A close pipe string features a blind end at the bottom, like a bit with blocked nozzles, a drilling pipe with a check valve, or a casing with a float collar. The close pipe string prevents the flow between the pipes and the annulus.

Two types of cutting plugs are considered in the model, namely, the porous cutting plug and the impermeable cutting plug. The porous cutting plug refers to an accumulated permeable cutting bulk (Figure 2), allowing the drilling fluid flow in the form of seepage. Further, due to the hydration expansion and dispersion of shale cutting particles, the pores in the cutting plug shrink and are blocked by fine dispersive particles. The porosity of the cutting plug reduced and finally an impermeable cutting plug is formed. Therefore, the impermeable cutting plug refers to an impermeable cutting bulk (Figure 3).

3.2.1. Porous Cutting Plug. The surge-swab pressure above a porous cutting plug is similar with that in a wellbore without a cutting plug, while the surge-swab pressure below the cutting plug equals the sum of two pressure losses: the frictional pressure loss along the annulus and the osmotic pressure loss at the porous cutting plug. The calculation of the frictional pressure loss in a steady-state model requires the effective velocity of drilling fluid, consisting of two components: the average velocity representing the flow rate of the drilling fluid and the cling velocity caused by pipe string axial motion.

The average velocity $v_{a}$ of drilling fluid in the annulus can be obtained [10]:

$$
v_{a}=\frac{4 Q_{a}}{\pi\left(D_{w}^{2}-D_{\mathrm{po}}^{2}\right)},
$$

in which, the flow rate in the annulus $Q_{a}$ of a closed pipe string condition is expressed as 


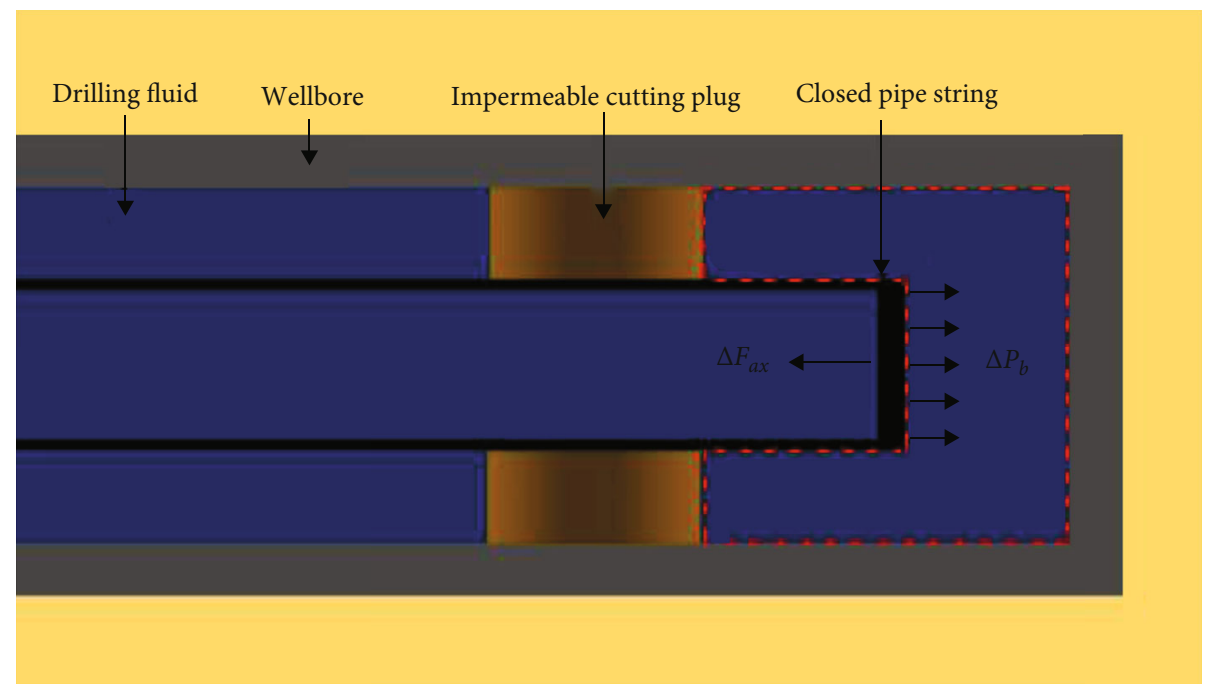

Figure 3: A closed pipe string with an impermeable cutting plug.

$$
Q_{a}=-\frac{\pi D_{\mathrm{po}}^{2} v_{t}}{4}
$$

The velocities from the well bottom to the ground in this paper are regarded positive. The clinging velocity of drilling fluid $v_{c}$ in the annulus depends on the tripping velocity of the pipe string $v_{t}$ :

$$
v_{c}=-C v_{t}
$$

in which, $C$ is the mud clinging constant $[10,18]$. Thus, the effective velocity of drilling fluid is expressed as

$$
v_{a e}=v_{a}+v_{c} .
$$

In this paper, the calculation method of frictional pressure in the annulus and pipes is referred to the literature of Fan [10] and $\mathrm{Li}$ et al. [5]. The frictional pressure loss in the annulus is obtained with the effective velocity $v_{a e}$ (the positive or the negative sign of the frictional pressure loss is the same of that of the effective velocity):

$$
\Delta p_{a}=\frac{2 f_{a} L \rho v_{a e}^{2}}{D_{w}-D_{\mathrm{po}}}
$$

in which, the frictional factor $f_{a}$ in the annulus is expressed as

$$
f_{a}=\frac{a}{\operatorname{Re}^{b}} .
$$

The constants $a$ and $b$ depends on the flow pattern of the drilling fluid. For laminar flow they are expressed as

$$
\left\{\begin{array}{l}
a=24 \\
b=1
\end{array}\right.
$$

and for turbulent flow, they are

$$
\left\{\begin{array}{l}
a=\frac{\lg n+3.93}{50}, \\
b=\frac{1.75-\lg n}{7} .
\end{array}\right.
$$

The Reynolds number of the flow in the annulus is expressed as

$$
\operatorname{Re}=\frac{12^{1-n} \rho\left(D_{w}-D_{p o}\right)^{n}\left|v_{a}\right|^{2-n}}{K_{c}(2 n+1 / 3 n)^{n}} .
$$

The second part of the surge-swab pressure results from the osmotic pressure loss at the porous cutting plug, obtained with the flow rate through it and its physical properties like the porosity and the cutting plug length (in the flow direction). For the power law fluid, the osmotic pressure can be derived from the superficial velocity $[34,35]$ through a porous material:

$$
\Delta p_{o}=\frac{2 K_{c}\left(4 Q_{a} /\left(D_{w}^{2}-D_{p}^{2}\right) \pi\right)}{\phi^{n}(n / 3 n+1)^{n} R_{c}^{1+n}} L_{p},
$$

in which, the capillary radius is obtained with the hydraulic radius [36]:

$$
R_{c}=2 R_{h}
$$

and the hydraulic radius is obtained with the porosity [37]:

$$
R_{h}=\frac{\phi D_{c}}{6(1-\phi)+\left(4 D_{c} / D_{w}\right)} .
$$

Therefore, the surge-swab pressure in the wellbore with a porous cutting plug is the sum of the frictional pressure loss and the osmotic pressure loss:

$$
\Delta p_{s}=\Delta p_{a}+\Delta p_{o}
$$




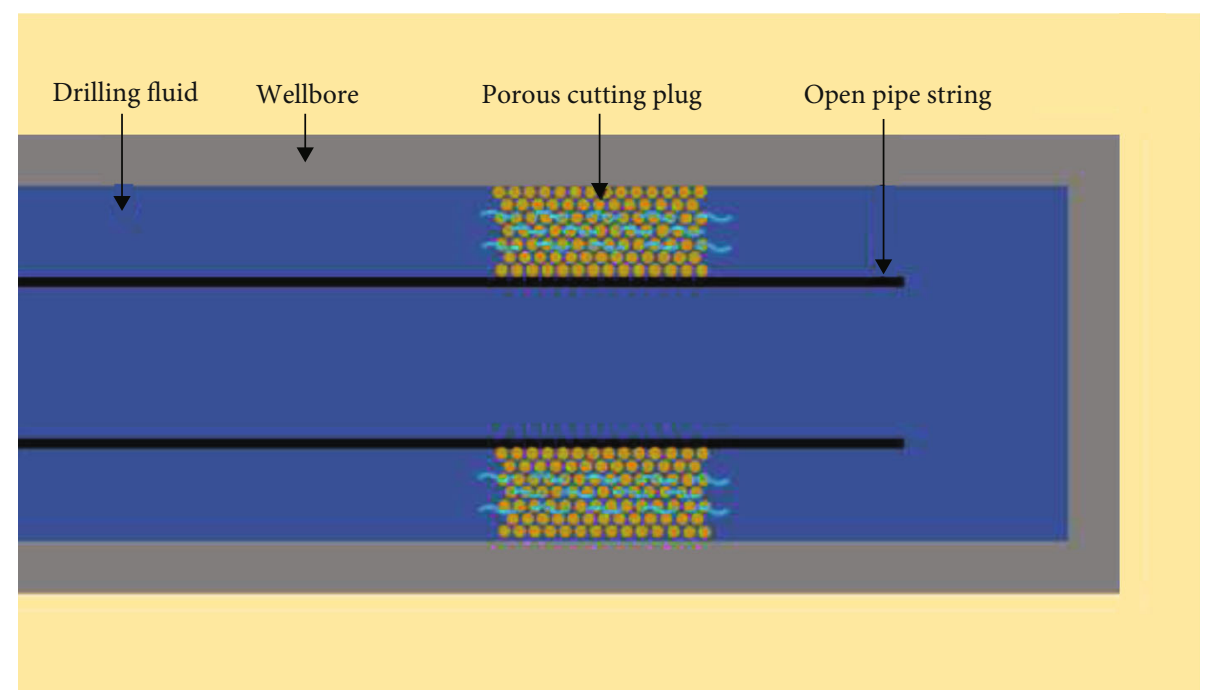

Figure 4: An open pipe string with a porous cutting plug.

The wellbore pressure at any given position in the annulus and below the pipe string can be obtained:

$$
p_{w}=p_{g}+\Delta p_{h}+\Delta p_{s}
$$

3.2.2. Impermeable Cutting Plug. The condition with both an impermeable cutting plug and a closed pipe string is the most dangerous for wellbore stability. Shown as the area surrounded by red dotted lines in Figure 3, the impermeable cutting plug, the wellbore, and the closed pipe string form an enclosed space. Without mass transfer between the enclosed space and its outside, the surge-swab pressure is not controlled by the frictional pressure loss and osmotic pressure loss. Considering the assumed incompressibility of the drilling fluid, the additional axial force on the closed bottom of the pipe string in tripping in or tripping out processes is directedly balanced by the additional hydraulic pressure in the enclosed space:

$$
\Delta F_{\mathrm{ax}}=\frac{\pi D_{b}^{2} \Delta p_{b}}{4}
$$

3.3. Open Pipe String. An open pipe string allows drilling fluid to flow between the annulus and the pipes during tripping processes through the access at the end of it, such as nozzles of the bit. Both the porous cutting plug and the impermeable cutting plug are considered with the open pipe string.

3.3.1. Porous Cutting Plug. With the porous cutting plug in the annulus, the drilling fluid is still allowed to flow (Figure 4). Therefore, the surge-swab pressure above and below the cutting plug are composed the same as those under the closed pipe string condition, while the flow rates and velocities required for calculation are different due to the mass exchange with the inside of pipes.

For a condition with both a porous cutting plug and an open pipe string, the flow rates in the annulus and the pipes satisfy the conservation of mass [10]:

$$
\frac{\pi\left(D_{w}^{2}-D_{\mathrm{po}}^{2}\right) v_{\mathrm{ae}}}{4}+\frac{\pi\left(D_{w}^{2}-D_{\mathrm{po}}^{2}\right) C v_{t}}{4}+\frac{\pi\left(D_{\mathrm{po}}^{2}-D_{\mathrm{pi}}^{2}\right) v_{t}}{4}+Q_{p}=0
$$

Similar to the closed pipe condition, the calculation of frictional pressure loss in the annulus requires the effective fluid velocity:

$$
v_{\mathrm{ae}}=-v_{t}\left(C+\frac{D_{\mathrm{po}}^{2}-D_{\mathrm{pi}}^{2}}{D_{w}^{2}-D_{\mathrm{po}}^{2}}\right)-\frac{4 Q_{p}}{\pi\left(D_{w}^{2}-D_{\mathrm{po}}^{2}\right)} .
$$

Then, frictional pressure loss in annulus $\Delta p_{a}$ can be obtained. The osmotic pressure can also be calculated with the method in the closed pipe string section, while the flow rate in the annulus $Q_{a}$ is expressed as

$$
Q_{a}=-\frac{\pi\left(D_{\mathrm{po}}^{2}-D_{\mathrm{pi}}^{2}\right) v_{t}}{4}-Q_{p}
$$

As shown above, the effective fluid velocity and the flow rate in the annulus cannot be calculated explicitly due to the unknown $Q_{p}$. A trial-and-error calculation is required here to determined $v_{\mathrm{ae}}$ and $Q_{a} . Q_{p}$ is adjusted to satisfy the pressure equality at the bottom of the pipe string [10]:

$$
p_{p 0}=p_{a 0}
$$

which indicates the wellbore pressure at the bottom calculated with the flow in the pipes equals that with the flow in the annulus.

To calculate the wellbore pressure at the bottom with the flow in the pipes, the frictional pressure loss in pipes is necessary $[10,38]$ : 


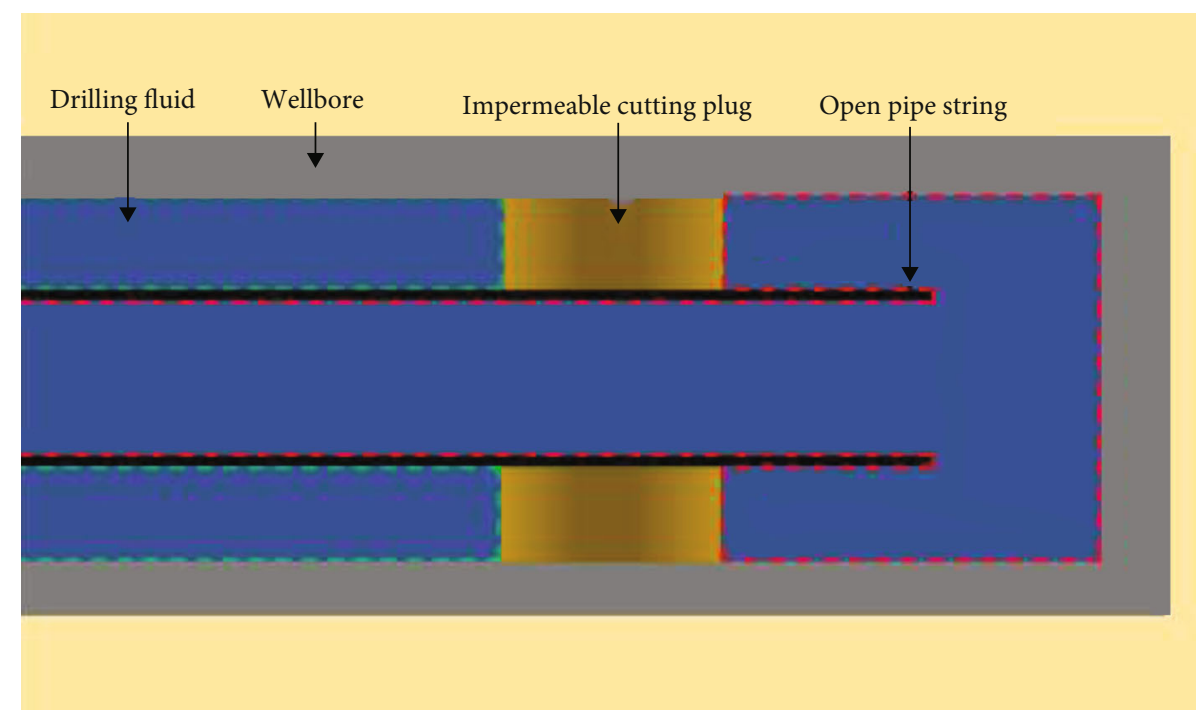

Figure 5: An open pipe string with an impermeable cutting plug.

$$
\Delta p_{p}=\frac{2 f_{p} L \rho v_{\mathrm{pe}}^{2}}{D_{\mathrm{pi}}},
$$

in which, the effective velocity of drilling fluid in pipes is the vector sum of the average velocity and the tripping velocity:

$$
v_{\mathrm{pe}}=v_{p}-v_{t}
$$

and the average velocity of drilling fluid in pipes is expressed as

$$
v_{p}=\frac{4 Q_{p}}{\pi D_{\mathrm{pi}}^{2}} .
$$

The friction factor for a pipe flow is similar to that in the annulus:

$$
f_{p}=\frac{a}{\operatorname{Re}^{b}}
$$

while the constants for laminar flow are different:

$$
\left\{\begin{array}{l}
a=16, \\
b=1
\end{array}\right.
$$

For turbulent flow, the calculation of constants $a$ and $b$ refers to Equation (8). The Reynolds number for the flow in pipes is expressed as

$$
\operatorname{Re}=\frac{8^{1-n} \rho D_{\mathrm{pi}}^{n} v_{\mathrm{pe}}^{2-n}}{K_{c}(3 n+1 / 4 n)^{n}} .
$$

Therefore, the surge-swab pressure in the annulus can be calculated. Similar to the closed pipe string condition, the wellbore pressure at any given position is obtained:
TABLE 1: Trajectory data of the horizontal well.

\begin{tabular}{lcc}
\hline Parameter & Value & Unit \\
\hline Length of the vertical section & 1956.3 & $\mathrm{~m}$ \\
Inclination at the kick off point & 0 & $\circ$ \\
Dogleg severity of the build-up section & 20.55 & $\% / 100 \mathrm{~m}$ \\
Inclination at the end of the build-up section & 90 & $\circ$ \\
Length of the horizontal section & 1500 & $\mathrm{~m}$ \\
\hline
\end{tabular}

TABLE 2: Input data of the model.

\begin{tabular}{lcc}
\hline Parameter & Value & Unit \\
\hline Outer diameter of the pipes & 137.9 & $\mathrm{~mm}$ \\
Inner diameter of the pipes & 118.6 & $\mathrm{~mm}$ \\
Diameter of the casing section & 224.41 & $\mathrm{~mm}$ \\
Diameter of the open-hole section & 215.9 & $\mathrm{~mm}$ \\
Drilling fluid density & 1500 & $\mathrm{Kg} / \mathrm{m}^{3}$ \\
Consistency coefficient & 0.75 & $\mathrm{~Pa} \cdot \mathrm{m}^{\mathrm{n}}$ \\
Liquidity index & 0.67 & - \\
Tripping out/in velocity & 0.65 & $\mathrm{~m} / \mathrm{s}$ \\
Clinging constant in casing section & 0.418 & - \\
Clinging constant in open-hole section & 0.426 & - \\
Porosity & 0.36 & - \\
Cutting particle diameter & 3 & $\mathrm{~mm}$ \\
Measured depth of the cutting bridge & 2500 & $\mathrm{~m}$ \\
Length of the cutting bridge & 1 & $\mathrm{~m}$ \\
\hline
\end{tabular}

$$
p_{w}=p_{g}+\Delta p_{h}+\Delta p_{s}
$$

3.3.2. Impermeable Cutting Plug. For the condition with the open pipe string and the impermeable cutting plug, the drilling fluid is divided into two spaces (Figure 5): (a) the space of the annulus above the impermeable cutting plug; (b) the 


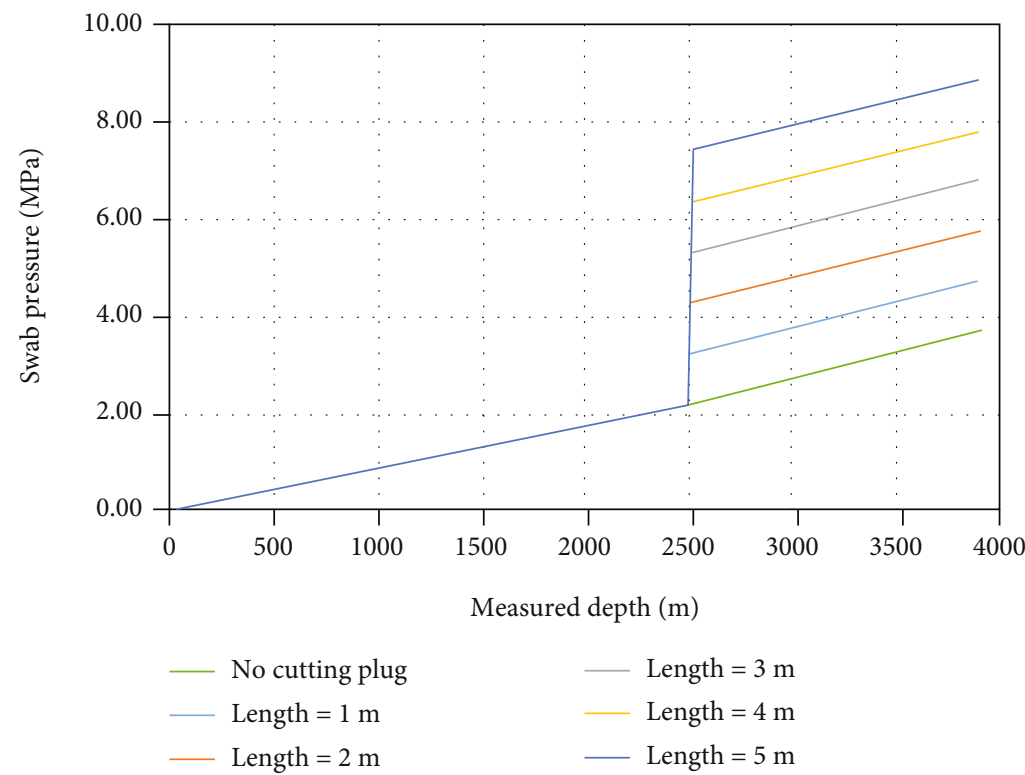

FIGURE 6: The effect of cutting plug length on the swab pressures in a closed pipe condition.

space composed by the annulus below the impermeable cutting plug, the wellbore below the bit, and the inside of the pipe string. The wellbore pressures (annulus pressures) in these two spaces should be calculated separately.

Due to the existence of the impermeable cutting plug, there is no flow rate in the annuli of both spaces. Therefore, the surge-swab pressures in the annuli are caused only by the clinging velocity:

$$
v_{\mathrm{ae}}=v_{c} \text {. }
$$

The wellbore pressure in the annulus above the impermeable cutting plug can be calculated with the surge-swab pressure and the hydrostatic pressure as usual, whereas the calculation in the annulus below the cutting plug is more complicated. The wellbore pressure $p_{a 0}$ at the bottom of the pipe string, equal to the pipe pressure $p_{b 0}$, is required as the boundary condition. $p_{a 0}$ is calculated with the hydrostatic pressure and the frictional pressure loss inside the pipes, in which the flow rate $Q_{p}$ is

$$
Q_{p}=-\frac{\pi\left(D_{\mathrm{po}}^{2}-D_{\mathrm{pi}}^{2}\right) v_{t}}{4}
$$
is

Therefore, the wellbore pressure above the cutting plug

$$
p_{w}=p_{g}+\Delta p_{h}+\Delta p_{s}
$$

The wellbore pressure between the cutting plug and the end of the pipe string is

$$
p_{w}=p_{a 0}-\Delta p_{h}-\Delta p_{s}
$$

The wellbore pressure below the end of the pipe string is

$$
p_{w}=p_{a 0}+\Delta p_{h}
$$

\section{Results and Discussion}

A horizontal well [39-41] is adopted to conduct a case study, consisting of a vertical section, a build-up section, and a horizontal section. The trajectory data and the input data of model calculation are separately presented in Tables 1 and 2 . The length of the horizontal section is assumed as $1500 \mathrm{~m}$. The casing shoe of the intermediate casing is assumed at the end of the build-up section $(2394.3 \mathrm{~m})$ for simplification. The case study is conducted for the swab pressure, while the surge pressure is exactly of the same magnitude with an opposite sign. The swab pressures are all calculated with the bit at the bottom of the wellbore $(3894.3 \mathrm{~m})$. The length of the cutting plug is only considered in the calculation of the osmotic pressure loss and ignored in the calculation of the wellbore pressure distribution.

4.1. Closed Pipe String. For a closed pipe string, the swab pressure distributions in tripping out processes with and without a cutting plug are compared in Figure 6, along with the effect of the cutting plug length. The swab pressures are calculated with of the length of 1 to $5 \mathrm{~m}$, respectively. Results show that, under the given condition, the swab pressures above the measured depth of the cutting plug $(2500 \mathrm{~m})$ are correspondingly identical, while below the cutting plugs, the swab pressures are all greater than those in a wellbore without a cutting plug. The swab pressures below the cutting plug increase with the increase of the cutting plug length, due to the greater osmotic pressure loss caused by a longer cutting plug. At the bottom of the wellbore, the swab pressure is $8.82 \mathrm{MPa}$ with a $5 \mathrm{~m}$ cutting plug, increasing by $244.9 \%$ of the swab pressure without a cutting plug $(3.60 \mathrm{MPa})$. 


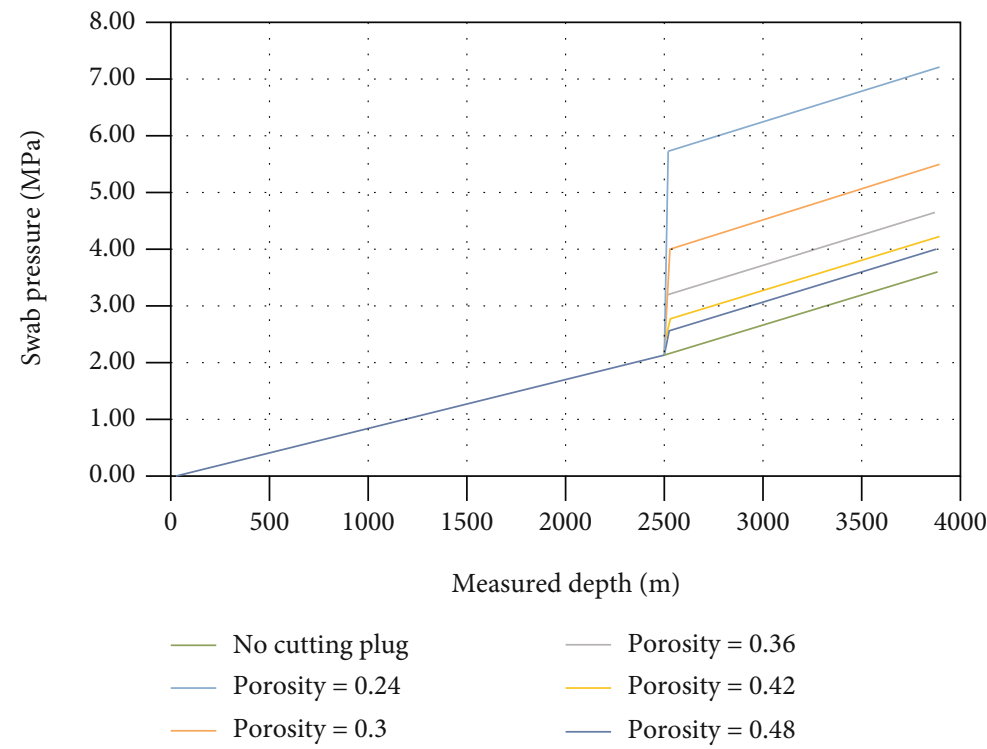

FIgURE 7: The effect of cutting plug porosity on the swab pressures in a closed pipe condition.
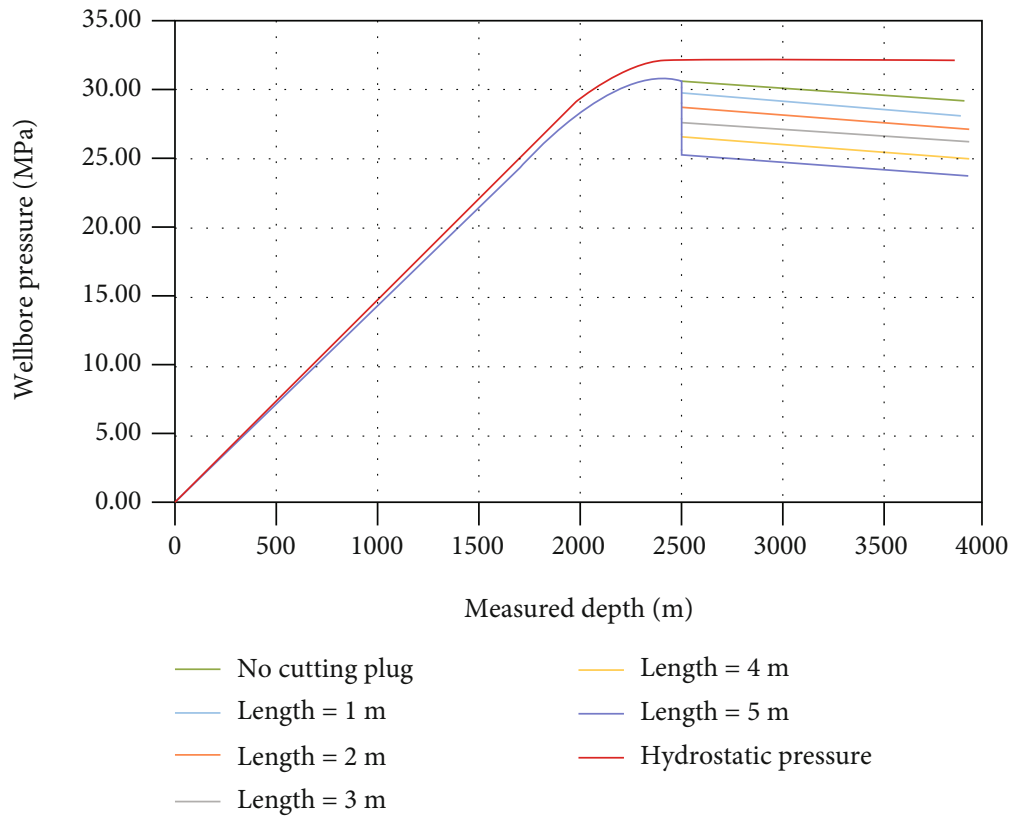

FIGURE 8: The effect of cutting plug length on the wellbore pressures in a closed pipe condition.

The effect of the porosity of the cutting plug on swab pressures is investigated and shown in Figure 7. The swab pressures are calculated with $0.24,0.3,0.36,0.42$, and 0.48 porosity, respectively. Similar with the trend of different cutting plug length, the results show that a lower porosity leads to a greater osmotic pressure loss, resulting in greater swab pressures below the measured depth of the cutting plug. At the bottom of the wellbore, the swab pressure is $7.18 \mathrm{MPa}$ with a 0.24 porosity, increasing by $199.0 \%$ of the swab pressure without a cutting plug.

Consequently, the wellbore pressures differ among the cutting plug conditions above. The effect of the cutting plug length on the wellbore pressures is shown in Figure 8. The wellbore pressures above the measured depth of the cutting plug $(2500 \mathrm{~m})$ are correspondingly identical. Those below the cutting plug decrease with the increase of the cutting plug length, due to the greater swab pressures. At the bottom of the well, the hydrostatic pressure is $32.86 \mathrm{MPa}$, the wellbore pressure without a cutting plug is $29.25 \mathrm{MPa}$, and the wellbore pressure with a $5 \mathrm{~m}$ cutting plug is 24.03 MPa, 5.22 MPa lower than that in the condition without a cutting plug. The effect of the porosity on the wellbore pressures is shown in Figure 9. The wellbore pressures below the cutting plug decrease with the decrease of the cutting plug porosity. At the bottom of the well, the wellbore pressure with a cutting plug featuring a porosity 


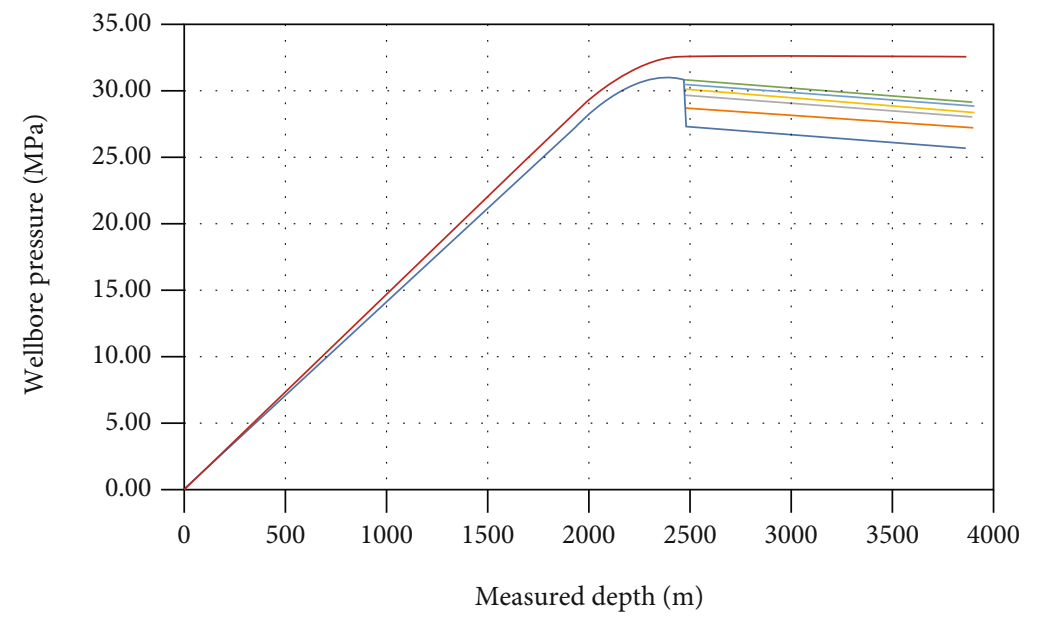

$\begin{array}{ll}- \text { No cutting plug } & - \text { Porosity }=0.42 \\ \text { Porosity }=0.24 & - \text { Porosity }=0.48 \\ - \text { Porosity }=0.3 & - \text { Hydrostatic pressure } \\ \text { Porosity }=0.36 & \end{array}$

FIgURE 9: The effect of cutting plug porosity on the wellbore pressures in a closed pipe condition.

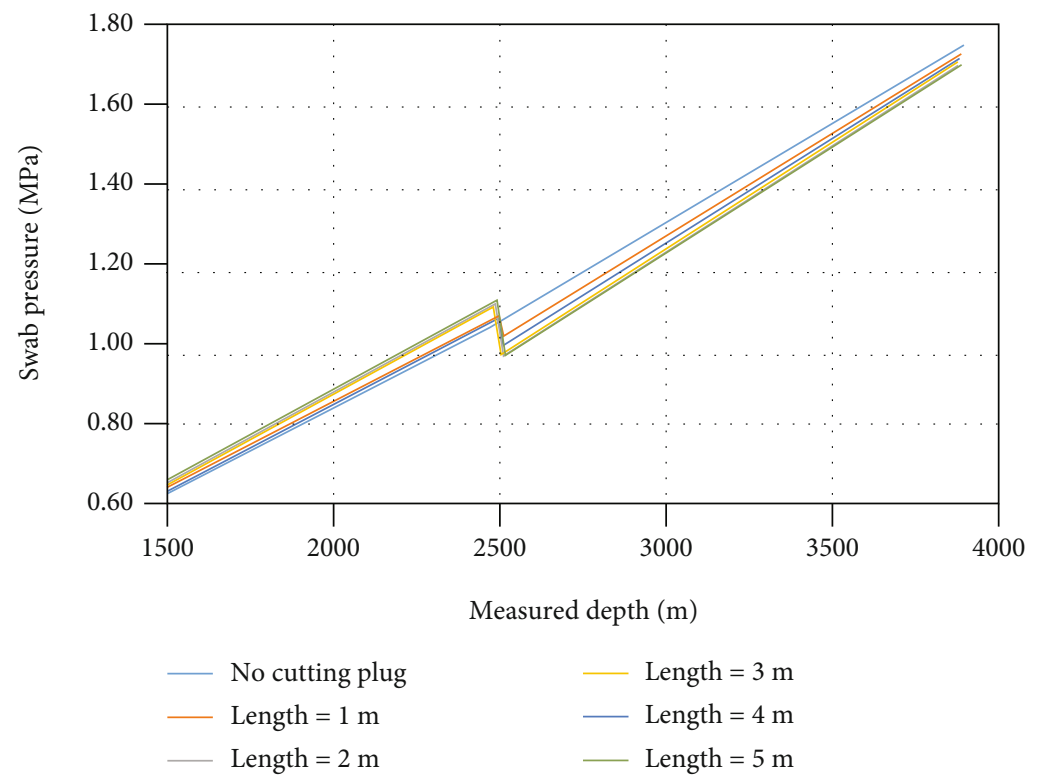

FIgURE 10: The effect of cutting plug length on the swab pressures in an open pipe condition.

0.24 is $25.68 \mathrm{MPa}, 3.57 \mathrm{MPa}$ lower than that in the condition without a cutting plug.

As analyzed above, an overestimation of the wellbore pressure would be generated by the previous no-cuttingplug model for a condition with cutting plugs. The overestimation is greater with the existence of a longer or low-porosity cutting plug, resulting in more risk on the wellbore stability.

4.2. Open Pipe String. The swab pressures are also calculated for an open pipe string with different cutting plug lengths, as shown in Figure 10. The swab pressures above the cutting plug measure depth are greater than those without a cutting plug, while the swab pressures below are lower. The difference increases with the length and is maximal near the cutting plug. Thus, the curve of swab pressures with shorter cutting plug is closer to the curve of no cutting plug. In the terms of quantity, at the measured depth of $2500 \mathrm{~m}$, the swab pressure of the no-cutting-plug condition is $1.05 \mathrm{MPa}$, while it is $1.11 \mathrm{MPa}$ of the $5 \mathrm{~m}$ cutting plug condition. At the measured depth of $2520 \mathrm{~m}$, the swab pressure of the no-cuttingplug condition is $1.06 \mathrm{MPa}$, while it is $0.97 \mathrm{MPa}$ of the $5 \mathrm{~m}$ cutting plug condition.

Similar tendency exists among different porosities of the cutting plug, as shown in Figure 11. With lower porosity, the swab pressures are higher above the cutting plug and lower 

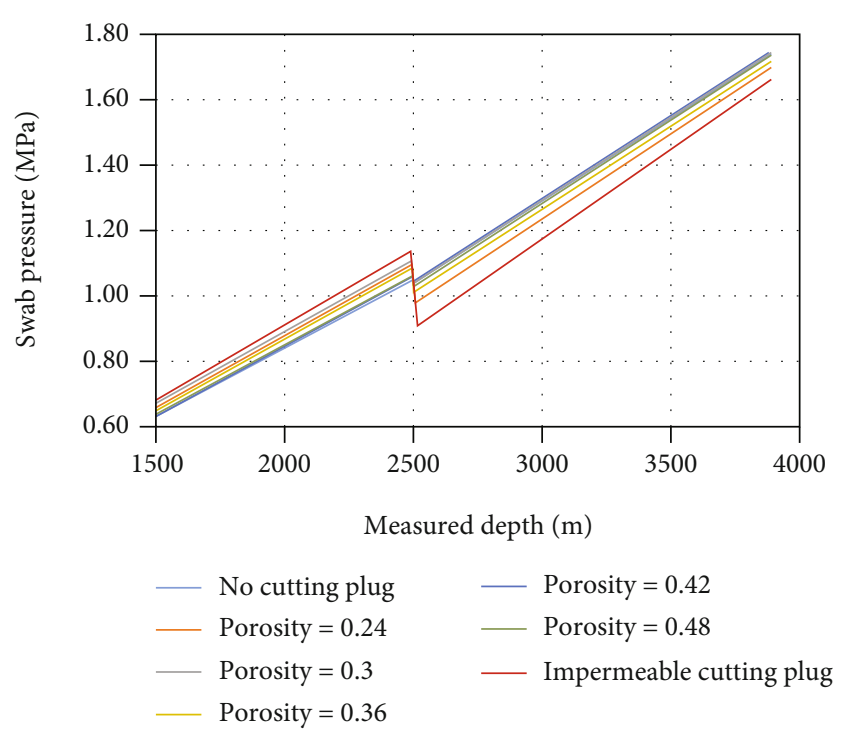

FIGURE 11: The effect of cutting plug porosity on the swab pressures in an open pipe condition.

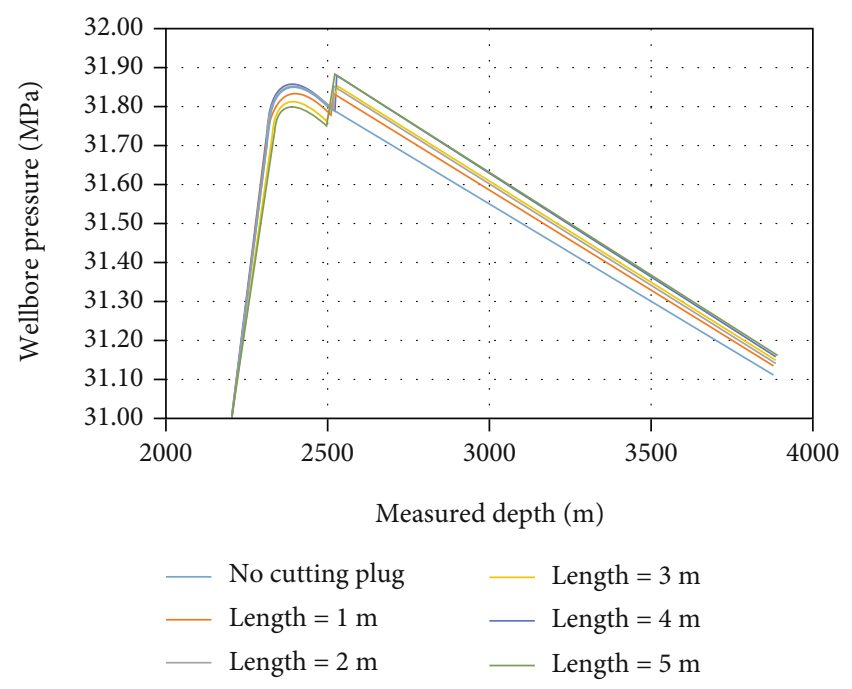

Figure 12: The effect of cutting plug length on the wellbore pressures in an open pipe condition.

below. The porosity of an impermeable cutting plug can be regarded as the lowest as 0 . Even the calculation of the impermeable cutting plug is different from that of a porous one, the result still satisfies the tendency. In the terms of quantity, the swab pressure of the impermeable cutting plug condition is $1.14 \mathrm{MPa}$ at the measured depth of $2500 \mathrm{~m}$ and $0.92 \mathrm{MPa}$ at $2520 \mathrm{~m}$.

The effect of the cutting plug length on the wellbore pressures is shown in Figure 12. Resulting from the swab pressure distribution, compared to the condition without a cutting plug, the wellbore pressures above the cutting plug are lower, and those below the cutting plug are higher. The wellbore pressure is $31.80 \mathrm{MPa}$ at $2500 \mathrm{~m}$ for the nocutting-plug wellbore, while it is $31.75 \mathrm{MPa}$ above the $5 \mathrm{~m}$ cutting plug at the same measured depth. The wellbore pressure is $31.79 \mathrm{MPa}$ at $2520 \mathrm{~m}$ for the no-cutting-plug well-

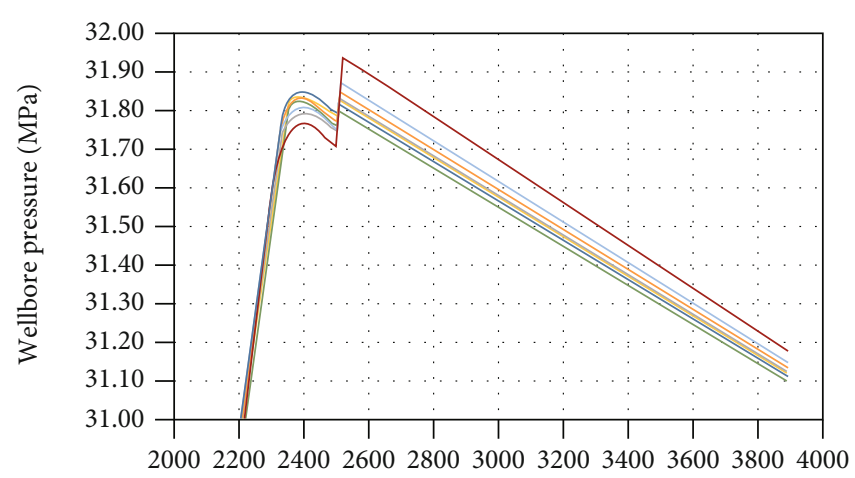

Measured depth (m)

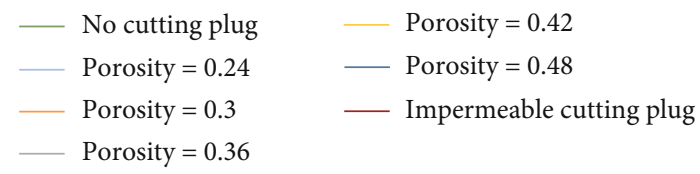

FIgURE 13: The effect of cutting plug porosity on the wellbore pressures in an open pipe condition.

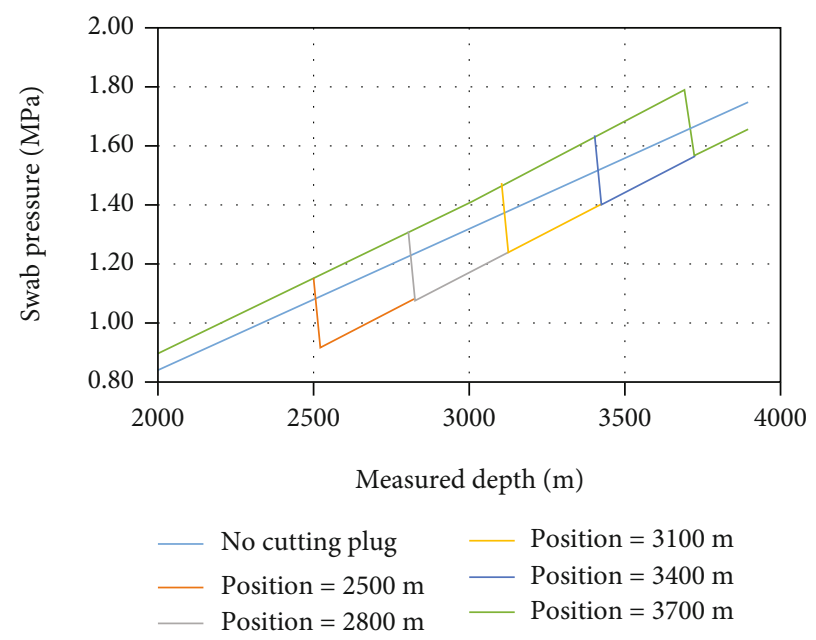

FIgURE 14: The effect of cutting plug position on the swab pressures in an open pipe condition.

bore, while it is $31.88 \mathrm{MPa}$ below the $5 \mathrm{~m}$ cutting plug at the same measured depth.

The effect of the cutting plug porosity on the wellbore pressures has a similar trend with the cutting plug length, shown in Figure 13. The cutting plug with lower porosity results in greater differences of wellbore pressures from those without a cutting plug. Therefore, the impermeable cutting plug has the greatest influence. In the terms of quantity, the wellbore pressure at $2500 \mathrm{~m}$ above the impermeable cutting plug is $31.71 \mathrm{MPa}$ and is $31.93 \mathrm{MPa}$ at $2520 \mathrm{~m}$ below it.

The difference of wellbore pressure distribution between the open pipe and the closed pipe conditions results from the difference between their annulus flow rates. In the condition of a closed pipe string, the flow rate in the annulus is independent on the length and the porosity of the cutting plug, whereas in the condition of an open pipe string, the flow rate 


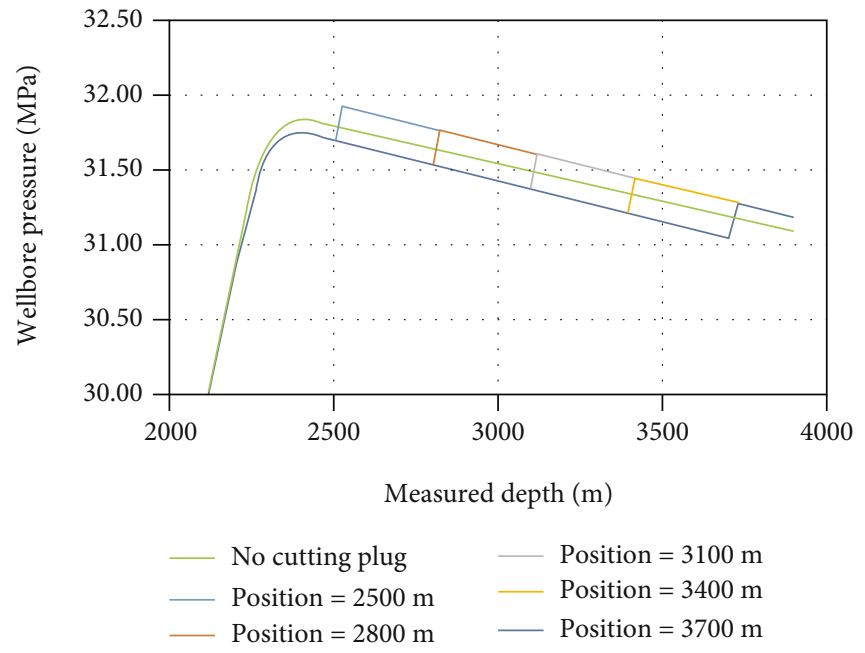

FIGURE 15: The effect of cutting plug position on the wellbore pressures in an open pipe condition.

decreases with the increase of the length and the decrease of the porosity of the cutting plug to satisfy the pressure balance at the joint of the annulus and the pipe inside.

The effect of the position of the cutting plug on the swab pressures is investigated. Swab pressures with an impermeable cutting plug at $2500 \mathrm{~m}, 2800 \mathrm{~m}, 3100 \mathrm{~m}, 3400 \mathrm{~m}$, and $3700 \mathrm{~m}$ are calculated, shown in Figure 14. Besides the aforementioned results, the swab pressure difference varies with the cutting plug position. The difference between of swab pressures above the cutting plug between the conditions with and without a cutting plug increases with the cutting plug measured depth, which means the error of the previous swab pressure model applied on a cutting-plug condition is greater. In the terms of quantity, the swab pressure above the $2500 \mathrm{~m}$ cutting plug is $1.14 \mathrm{MPa}$ and is $1.05 \mathrm{MPa}$ without a cutting plug, resulting in a difference of $0.09 \mathrm{MPa}$, while the swab pressure above the $3700 \mathrm{~m}$ cutting plug is $1.80 \mathrm{MPa}$ and is $1.65 \mathrm{MPa}$ without a cutting plug, resulting in a difference of $0.15 \mathrm{MPa}$. Correspondingly, the difference of wellbore pressures above the cutting plug increases with the measured depth of it, shown in Figure 15. Consequently, the wellbore instability risk of application of the previous swab pressure model in a cutting plug condition is higher with a deeper cutting plug.

\section{Conclusions}

(1) A surge-swab pressure model is established considering the effect of cutting plugs, which is not considered in existing surge-swab pressure models. Both the open pipe string and closed pipe string conditions are considered. Cutting plug might develop from a porous one into an impermeable one due to clay hydration and dispersion of shale, resulting in the difference of pressure calculation

(2) A cutting plug in the closed pipe string condition has significant influence on surge-swab pressures. The surge-swab pressures above the cutting plug measured depth are identical to those without a cutting plug, while the surge-swab pressures below increase with the increase of the cutting plug length and the decrease of the cutting plug porosity. Quantitively, at the bottom of the wellbore, the swab pressure is $8.82 \mathrm{MPa}$ with a $5 \mathrm{~m}$ cutting plug (porosity $=0.36$ ) and $7.18 \mathrm{MPa}$ with a 0.24 porosity (cutting plug length $=1 \mathrm{~m}$ ), respectively, $244.9 \%$ and $199.0 \%$ of the swab pressure without a cutting plug (3.60 MPa). Consequently, the previous model overestimates the wellbore pressure for 5.22 MPa with a $5 \mathrm{~m}$ cutting plug and for $3.57 \mathrm{MPa}$ with a 0.24 porosity cutting plug, resulting in the risk of inappropriate wellbore pressure management

(3) A cutting plug in the open pipe condition brings in more complicated influence on surge-swab pressures. Compared to the condition without a cutting plug, the surge-swab pressures are higher above the cutting plug measured depth and lower below. The difference increases with the decrease of the cutting plug porosity and the distance from the cutting plug and the increase of the length of the cutting plug. The difference above the cutting plug increases with the measured depth of the cutting plug. Quantitively, at the measured depth of $2500 \mathrm{~m}$, the swab pressure of the no-cutting-plug condition is $1.05 \mathrm{MPa}$, while it is $1.11 \mathrm{MPa}$ of the $5 \mathrm{~m}$ cutting plug condition and $1.14 \mathrm{MPa}$ of the impermeable cutting plug condition. Compared to the cutting plug at $2500 \mathrm{~m}$, the swab pressure above the $3700 \mathrm{~m}$ impermeable cutting plug is $1.80 \mathrm{MPa}$ and is $1.65 \mathrm{MPa}$ of the no-cutting-plug condition

(4) The model proposed in this work reveals extra surgeswab pressures and hazardous wellbore pressures under the effect of cutting plugs ignored by previous models, detecting potential wellbore instability risk of previous models. The model can be applied in field practice to guide the optimization of tripping parameters and guarantee the wellbore stability of shale drilling 


\section{Appendix}

The calculation procedure for all four cases of the model in Section 3 (establishment of model) is systematized for the convenience of readers and users. Relevent references are denoted in Section 3.

\section{A.1. Closed Pipe String with a Porous Cutting Plug}

Calculate the flow rate in the annulus $Q_{a}$ :

$$
Q_{a}=-\frac{\pi D_{\mathrm{po}}^{2} v_{t}}{4}
$$

Calculate the average velocity $v_{a}$ of drilling fluid in the annulus:

$$
v_{a}=\frac{4 Q_{a}}{\pi\left(D_{w}^{2}-D_{\mathrm{po}}^{2}\right)} .
$$

Calculate the clinging velocity $v_{c}$ of drilling fluid in the annulus:

$$
v_{c}=-C v_{t}
$$

Combining Eq. (A.2) and Eq. (A.3), calculate the effective velocity $v_{\mathrm{ae}}$ of drilling fluid in the annulus:

$$
v_{\mathrm{ae}}=v_{a}+v_{c} .
$$
lus:

Calculate the Reynolds number of the flow in the annu-

$$
\operatorname{Re}=\frac{12^{1-n} \rho\left(D_{w}-D_{\mathrm{po}}\right)^{n}\left|v_{a}\right|^{2-n}}{K_{c}(2 n+1 / 3 n)^{n}} .
$$

For laminar flow, constants $a$ and $b$ are:

$$
\left\{\begin{array}{l}
a=24 \\
b=1
\end{array}\right.
$$

For turbulent flow, constants $a$ and $b$ are

$$
\left\{\begin{array}{l}
a=\frac{\lg n+3.93}{50}, \\
b=\frac{1.75-\lg n}{7} .
\end{array}\right.
$$

Calculate the frictional factor in the annulus $f_{a}$ :

$$
f_{a}=\frac{a}{\operatorname{Re}^{b}}
$$

Combining Eq. (A.4) and Eq. (A.8), calculate the frictional pressure loss in the annulus $\Delta p_{a}$ :

$$
\Delta p_{a}=\frac{2 f_{a} L \rho v_{\mathrm{ae}}^{2}}{D_{w}-D_{\mathrm{po}}} .
$$

Calculate the hydraulic radius $R_{h}$ :

$$
R_{h}=\frac{\phi D_{c}}{6(1-\phi)+\left(4 D_{c} / D_{w}\right)} .
$$

Calculate the capillary radius $R_{c}$ :

$$
R_{c}=2 R_{h}
$$

Calculate the osmotic pressure $\Delta p_{o}$ :

$$
\Delta p_{o}=\frac{2 K_{c}\left(4 Q_{a} /\left(D_{w}^{2}-D_{p}^{2}\right) \pi\right)}{\phi^{n}(n / 3 n+1)^{n} R_{c}^{1+n}} L_{p} .
$$

Combining (A.9) and (A.12), calculate the surge-swab pressure $\Delta p_{s}$ :

$$
\Delta p_{s}=\Delta p_{a}+\Delta p_{o}
$$

Calculate the wellbore pressure $p_{w}$ :

$$
p_{w}=p_{g}+\Delta p_{h}+\Delta p_{s}
$$

\section{A.2. Closed Pipe String with an Impermeable Cutting Plug}

$$
\Delta p_{b}=\frac{4 \Delta F_{\mathrm{ax}}}{\pi D_{b}^{2}}
$$

Calculate the wellbore pressure $p_{w}$ :

$$
p_{w}=p_{g}+\Delta p_{h}+\Delta p_{b}
$$

\section{A.3. Open Pipe String with a Porous Cutting Plug}

Trial-and-error is needed to calculate the effective fluid velocity $v_{\mathrm{ae}}$ and the flow rates $Q_{a}$ in the annulus due to the unknown $Q_{p}$.

Assume an initial $Q_{p}$, calculate the effective velocity $v_{\mathrm{ae}}$ of drilling fluid in the annulus:

$$
v_{\mathrm{ae}}=-v_{t}\left(C+\frac{D_{\mathrm{po}}^{2}-D_{\mathrm{pi}}^{2}}{D_{w}^{2}-D_{\mathrm{po}}^{2}}\right)-\frac{4 Q_{p}}{\pi\left(D_{w}^{2}-D_{\mathrm{po}}^{2}\right)} .
$$

Calculate the frictional pressure loss $\Delta p_{a}$ with Eq. (A.9). 
Calculate the flow rate in the annulus $Q_{a}$ :

$$
Q_{a}=-\frac{\pi\left(D_{\mathrm{po}}^{2}-D_{\mathrm{pi}}^{2}\right) v_{t}}{4}-Q_{p} .
$$

Calculate the osmotic pressure $\Delta p_{o}$ with Eq. (A.12).

Calculate the surge-swab pressure $\Delta p_{s}$ with Eq. (A.13).

Calculate the wellbore pressure $p_{w}$ at the bottom of the pipe string with Eq. (A.14), namely, $p_{a 0}$ :

$$
p_{a 0}=p_{w}
$$

Calculate the velocity of drilling fluid in pipes $v_{p}$ :

$$
v_{p}=\frac{4 Q_{p}}{\pi D_{\mathrm{pi}}^{2}} .
$$

Calculate the effective velocity of drilling fluid in pipes:

$$
v_{\mathrm{pe}}=v_{p}-v_{t}
$$

Calculate the Reynolds number for the flow in pipes:

$$
\operatorname{Re}=\frac{8^{1-n} \rho D_{\mathrm{pi}}^{n} v_{\mathrm{pe}}^{2-n}}{K_{c}(3 n+1 / 4 n)^{n}} .
$$

For laminar flow, constants $a$ and $b$ are

$$
\left\{\begin{array}{l}
a=16 \\
b=1
\end{array}\right.
$$

For turbulent flow, constants $a$ and $b$ refer to Eq. (A.7). Calculate the friction factor in the pipes $f_{p}$ :

$$
f_{p}=\frac{a}{\operatorname{Re}^{b}}
$$

Calculate the frictional pressure loss in pipes $\Delta p_{p}$ :

$$
\Delta p_{p}=\frac{2 f_{p} L \rho v_{\mathrm{pe}}^{2}}{D_{\mathrm{pi}}} .
$$

Calculate the wellbore pressure $p_{w}$ at the bottom of the pipe string, namely $p_{p 0}$ :

$$
p_{p 0}=p_{g}+\Delta p_{h}+\Delta p_{p}
$$

With Eq. (A.19) and Eq. (A.25), adjust $Q_{p}$ until the pressure equality at the bottom of the pipe string is satisfied:

$$
p_{p 0}=p_{a 0}
$$

With determined $Q_{p}$, all the parameters for calculating $p_{w}$ with Eq. (A.14) is obtained.

\section{A.4. Open Pipe String with an Impermeable Cutting Plug}

Calculate the effective velocity $v_{a e}$ of drilling fluid in the annulus:

$$
v_{\mathrm{ae}}=v_{c} .
$$

Calculate the frictional pressure loss in the annulus $\Delta p_{a}$ with Eq. (A.9).

Calculate the surge-swab pressure $\Delta p_{s}$ :

$$
\Delta p_{s}=\Delta p_{a}
$$

Calculate the flow rate in the pipes $Q_{p}$ :

$$
Q_{p}=-\frac{\pi\left(D_{\mathrm{po}}^{2}-D_{\mathrm{pi}}^{2}\right) v_{t}}{4} .
$$

With Eq. (A.26), calculate the wellbore pressure $p_{w}$ at the bottom of the pipe string, namely, $p_{p 0}$.

Calculate the wellbore pressure above the cutting plug:

$$
p_{w}=p_{g}+\Delta p_{h}+\Delta p_{s}
$$

Calculate the wellbore pressure between the cutting plug and the end of the pipe string:

$$
p_{w}=p_{p 0}-\Delta p_{h}-\Delta p_{s}
$$
string

Calculate the wellbore pressure below the end of the pipe

$$
p_{w}=p_{p 0}+\Delta p_{h}
$$

\section{Nomenclature}

a: Constant for frictional factor calculation, dimensionless

b: Constant for frictional factor calculation, dimensionless

C: $\quad$ Mud clinging constant, dimensionless

$D_{b}$ : Diameter of the bit, $\mathrm{m}$

$D_{c}$ : $\quad$ Cutting particle diameter, $\mathrm{m}$

$D_{w}$ : Diameter of the wellbore, $\mathrm{m}$

$D_{\text {po }}$ : Outer diameter of the pipe string, $\mathrm{m}$

$D_{\mathrm{pi}}$ : Inner diameter of the pipe string, $\mathrm{m}$

$f_{a}$ : Frictional factor in the annulus, dimensionless

$f_{p}$ : Frictional factor in the pipes, dimensionless

$K_{c}: \quad$ Consistency coefficient, $\mathrm{Pa} \cdot \mathrm{m}^{\mathrm{n}}$

$L: \quad$ Length of the flow channel, $\mathrm{m}$

$L_{p}: \quad$ Length of the cutting plug, $\mathrm{m}$

$n$ : $\quad$ Flow behavior index, dimensionless

$p_{g}: \quad$ Wellbore pressure at the ground surface, $\mathrm{Pa}$

$p_{a 0}$ : Annulus pressure at the bottom of the pipe string, $\mathrm{Pa}$

$p_{p 0}$ : Pipe pressure at the bottom of the pipe string, $\mathrm{Pa}$

$p_{w}$ : Wellbore pressure, $\mathrm{Pa}$ 
$Q_{a}: \quad$ Flow rate in the annulus, $\mathrm{m}^{3} / \mathrm{s}$

$Q_{p}: \quad$ Flow rate in the pipes, $\mathrm{m}^{3} / \mathrm{s}$

$R_{c}$ : Capillary radius of the porous cutting plug, $\mathrm{m}$

$R_{h}$ : Hydraulic radius of the porous cutting plug, $m$

Re: Reynolds number, dimensionless

$v_{a}$ : Average velocity of drilling fluid in the annulus, $\mathrm{m} / \mathrm{s}$

$v_{\mathrm{ae}}$ : Effective velocity of drilling fluid in the annulus, $\mathrm{m} / \mathrm{s}$

$v_{p}$ : Average velocity of drilling fluid in the pipes, $\mathrm{m} / \mathrm{s}$

$v_{\mathrm{pe}}:$ Effective velocity of drilling fluid in the pipes, $\mathrm{m} / \mathrm{s}$

$v_{c}$ : Clinging velocity of drilling fluid, $\mathrm{m} / \mathrm{s}$

$v_{t}: \quad$ Tripping velocity of the pipe string, $\mathrm{m} / \mathrm{s}$

$\Delta F_{\mathrm{ax}}$ : Pipe string axial force applied on the bit, $\mathrm{N}$

$\Delta p_{a}:$ Frictional pressure loss in the annulus, $\mathrm{Pa}$

$\Delta p_{b}$ : Difference of the hydraulic pressure applied on the bit, Pa

$\Delta p_{h}: \quad$ Hydrostatic pressure, $\mathrm{Pa}$

$\Delta p_{o}:$ Osmotic pressure loss, $\mathrm{Pa}$

$\Delta p_{p}: \quad$ Frictional pressure loss in the pipes, $\mathrm{Pa}$

$\Delta p_{s}:$ Surge-swab pressure, $\mathrm{Pa}$

$\rho: \quad$ Drilling fluid density, $\mathrm{kg} / \mathrm{m}^{3}$

$\phi$ : $\quad$ Porosity of the porous cutting plug, dimensionless

\section{Data Availability}

The data used to support the findings of this study are included within the article.

\section{Conflicts of Interest}

The authors declare that there are no conflicts of interest regarding the publication of this paper.

\section{Acknowledgments}

The authors gratefully acknowledge the support of the National Natural Science Foundation of China (U19B6003; 51734010) and the Strategic Cooperation Technology Projects of CNPC and CUPB (ZLZX2020-01).

\section{References}

[1] C. N. Zou, Z. Yang, J. W. Cui et al., "Formation mechanism, geological characteristics and development strategy of nonmarine shale oil in China," Petroleum Exploration and Development, vol. 40, no. 1, pp. 15-27, 2013.

[2] Z. J. Jin, Z. R. Bai, B. Gao, and M. W. Li, "Has China ushered in the shale oil and gas revolution," Oil \& Gas Geology, vol. 40, no. 3, pp. 451-458, 2019.

[3] Q. Lei, D. W. Weng, S. C. Xiong et al., "Progress and development directions of shale oil reservoir stimulation technology of China National Petroleum Corporation," Petroleum Exploration and Development, vol. 48, no. 5, pp. 11981207, 2021.

[4] Q. Fu, "The status, challenge and prospect of shale oil exploration and development in China," Oil Drilling \& Production Technology, vol. 27, no. 4, pp. 58-62, 2015.

[5] X. Li, D. L. Gao, Y. C. Zhou, and W. K. Cao, "General approach for the calculation and optimal control of the extended-reach limit in horizontal drilling based on the mud weight window,"
Journal of Natural Gas Science and Engineering, vol. 35, pp. 964-979, 2016.

[6] Y. H. Shi, H. Q. Xia, M. Peng, Y. Chen, and Y. J. Chen, "New accurate prediction method of safe window of drilling fluid density," Fault-block Oil \& Gas Field, vol. 26, no. 2, pp. 248-252, 2019.

[7] H. Wang, R. Sweatman, B. Engleman et al., "Best practice in understanding and managing lost circulation challenges," SPE Drilling \& Completion, vol. 23, no. 2, pp. 168-175, 2008.

[8] X. W. Jiang, Drilling Accidents and Complex Problems, Petroleum Industry Press, Beijing, 2006.

[9] N. Khakzad, F. Khan, and P. Amyotte, "Quantitative risk analysis of offshore drilling operations: a Bayesian approach," Safety Science, vol. 57, pp. 108-117, 2013.

[10] H. H. Fan, Practical Drilling Fluid Mechanics, Petroleum Industry Press, Beijing, 2014.

[11] G. E. Cannon, "Changes in hydrostatic pressure due to withdrawing drill pipe from the hole," in Drilling and Production Practices, pp. 42-47, One Petro, 1934.

[12] A. Wolski, S. L. M. Junqueira, and C. O. R. Negrão, “A steady-state approach for evaluation of surge and swab pressures in flows with free surface boundary conditions," Journal of Petroleum Science and Engineering, vol. 122, pp. 208-215, 2014.

[13] S. M. He, R. Srivastav, M. Tang, and R. Ahmed, "A new simplified surge and swab pressure model for yield-power-law drilling fluids," Journal of Natural Gas Science and Engineering, vol. 28, pp. 184-192, 2016.

[14] S. Krishna, S. Ridha, S. Campbell, S. U. Ilyas, I. Dzulkarnain, and M. Abdurrahman, "Experimental evaluation of surge/ swab pressure in varying annular eccentricities using nonNewtonian fluid under Couette-Poiseuille flow for drilling applications," Journal of Petroleum Science and Engineering, vol. 206, article 108982, 2021.

[15] G. R. Samuel, A. Sunthankar, G. McColpin, P. Bern, and T. Flynn, "Field validation of transient swab-surge response with real-time downhole pressure data," SPE Drilling \& Completion, vol. 18, no. 4, pp. 280-283, 2003.

[16] R. Srivastav, M. Enfis, F. Crespo, R. Ahmed, A. Saasen, and M. Laget, "Surge and swab pressures in horizontal and inclined wells," in In Paper SPE 152662 Presented at the SPE Latin America and Caribbean Petroleum Engineering Conference, Mexico City, Mexico, 2012.

[17] E. H. Clark, "Bottom-hole pressure surges while running pipe," in In Paper 54-PET-22 Presented at the Petroleum Mechanical Engineering Conference, Los Angeles, California, USA, 1954.

[18] J. A. Burkhardt, "Wellbore pressure surges produced by pipe movement," Journal of Petroleum Technology, vol. 13, no. 6, pp. 595-605, 1961.

[19] J. E. Fontenot and R. K. Clark, "an improved method for calculating swab and surge pressures and circulating pressures in a drilling well," Society of Petroleum Engineers Journal, vol. 14, no. 5, pp. 451-462, 1974.

[20] H. G. Wang and X. S. Liu, "Study on steady surge pressure for yield-pseudoplastic fluid in a concentric annulus," Applied Mathematics and Mechanics, vol. 17, no. 1, pp. 15-23, 1996.

[21] H. G. Wang, X. S. Liu, and J. Dong, "Approximate solution of stable fluctuation pressure of Newtonian fluid in eccentric annular," Oil Drilling \& Production Technology, vol. 18, no. 2, pp. 18-21, 1996. 
[22] F. Crespo, R. Ahmed, M. Enfis, A. Saasen, and M. Amani, "Surge-and-swab pressure predictions for yield-power-law drilling fluids," SPE Drilling \& Completion, vol. 27, no. 4, pp. 574-585, 2012.

[23] F. Crespo and R. Ahmed, "A simplified surge and swab pressure model for yield power law fluids," Journal of Petroleum Science and Engineering, vol. 101, pp. 12-20, 2013.

[24] M. Tang, J. Y. Xiong, and S. M. He, “A new model for computing surge/swab pressure in horizontal wells and analysis of influencing factors," Journal of Natural Gas Science and Engineering, vol. 19, pp. 337-343, 2014.

[25] A. Ettehadi and G. Altun, "Functional and practical analytical pressure surges model through Herschel Bulkley fluids," Journal of Petroleum Science and Engineering, vol. 171, pp. 748759, 2018.

[26] S. Krishna, S. Ridha, P. Vasant, S. U. Ilyas, S. Irawan, and R. Gholami, "Explicit flow velocity modelling of yield powerlaw fluid in concentric annulus to predict surge and swab pressure gradient for petroleum drilling applications," Journal of Petroleum Science and Engineering, vol. 195, article 107743, 2020.

[27] A. Lubinski, F. Hsu, and K. Nolte, "Transient pressure surges due to pipe movement in an oil well," Oil \& Gas Science Technology, vol. 32, no. 3, pp. 307-348, 1977.

[28] M. Lal, "Surge and swab modeling for dynamic pressures and safe trip velocities," in In Paper IADC/SPE 11412 Presented at the IADC/SPE 1983 Drilling Conference, New Orleans, Louisiana, USA, 1983.

[29] R. F. Mitchell, "Dynamic Surge/Swab pressure predictions," SPE Drilling Engineering, vol. 3, no. 3, pp. 325-333, 1988.

[30] R. F. Mitchell, "Surge pressures in low-clearance liners," in In Paper IADC/SPE 87181 Presented at the IADC/SPE Drilling Conference, Dallas, Texas, USA, 2004.

[31] V. Tikhonov, O. Bukashkina, V. Liapidevskii, and L. Ring, "Development of model and software for simulation of surge-swab process at drilling," in In Paper SPE 181933 Presented at the SPE Russian Petroleum Technology Conference and Exhibition, Moscow, Russia, 2016.

[32] A. Willersrud, L. Imsland, and M. Blanke, "Early pack-off diagnosis in drilling using an adaptive observer and statistical change detection," IFAC-PapersOnLine, vol. 48, no. 6, pp. 177-182, 2015.

[33] X. Li, D. L. Gao, Y. C. Zhou, H. Zhang, and Y. C. Yang, "Study on the prediction model of the open-hole extended-reach limit in horizontal drilling considering the effects of cuttings," Journal of Natural Gas Science and Engineering., vol. 40, pp. 159167, 2017.

[34] Z. Q. Yang, J. Lu, Y. Wang et al., "Column penetration grouting mechanism for power-law fluids considering tortuosity effect of porous media," Chinese Journal of Rock Mechanics and Engineering., vol. 40, no. 2, pp. 410-418, 2021.

[35] X. Y. Kong, Advanced Seepage Mechanics, University of Science and Technology of China Press, Hefei, 2010.

[36] J. S. Wu, Analysis of Resistance for Flow through Porous Media [M.S. thesis], Huazhong University of Science and Technology, Wuhan, 2006.

[37] X. W. Tian, P. Wang, and S. M. Xu, "Flow resistance characteristics of power law fluid flow through granular porous medium," Journal of Harbin Institute of Technology, vol. 49, no. 1, pp. 126-132, 2017.
[38] X. Li, D. L. Gao, B. P. Lu, Y. J. Zeng, J. C. Zhang, and S. M. Zhou, "Study on the prediction model of extended-reach limit length in horizontal drilling with dual-channel drillpipe in shale formation," Journal of Petroleum Science and Engineering, vol. 177, pp. 570-578, 2019.

[39] X. Li, D. L. Gao, B. P. Lu, Y. J. Zeng, and J. C. Zhang, "Study on modified maximum extension length prediction model for horizontal wells considering differential sticking," Journal of Petroleum Science and Engineering., vol. 183, article 106371, 2019.

[40] T. G. Chen, Z. C. Guan, and X. S. Liu, Theories and Technologies of Drilling Engineering, China University of Petroleum Press, Dongying, 2006.

[41] K. Lin, J. J. Wang, Z. X. Shen, W. H. Liu, J. D. Wang, and F. S. Shangguan, Drilling Handbook: Chapter 3, Petroleum Industry Press, Beijing, 2013. 